\title{
DESDE LA HISTORIA DE LA EDUCACIÓN: EDUCACIÓN Y MUNDO RURAL
}

\section{From the History of Education: Education and rural world}

\author{
Alicia Civera Cerecedo* y Antón Costa Rico ${ }^{\&}$
}

Los diversos procesos históricos de educación, con sus puntos de partida, sus intenciones y su relativa y específica institucionalización, se presentan ante nosotros en forma de plural manifestación a lo largo del tiempo, de los espacios y de las culturas. Es esta pluralidad la que también está presente cuando, haciendo un recorte de los espacios sociales, nos referimos a los espacios rurales.

A pesar de que con altísima frecuencia aludimos a «la escuela rural», como podríamos hacerlo a «la escuelas o escuelas urbanas» y bien que a menudo encontramos títulos bibliográficos o de informes que aluden a «la escuela rural», sean estos elaborados en el plano académico o desde el ámbito de los organismos internacionales, en realidad la expresión «educación rural» alude a formas y experiencias diferentes en que la escuela se ha instalado en zonas rurales, a veces como una específica modalidad educativa en relación a los escenarios rurales, aunque en la mayor parte de las veces no se ha tratado de un proyecto específico para la ruralidad. Todo lo cual no nos impide afirmar que, por encima de fronteras políticas u otras culturales, lingüísticas, pedagógicas, económicas o sociales, las instituciones de formación escolar que se sitúan en ámbitos rurales, tien-

\footnotetext{
" Departamento de Investigaciones Educativas (DIE), Centro de Investigación y de Estudios Avanzados del Instituto Politécnico Nacional Sede Sur (Cinvestav), Calzada de los Tenorios 235, Col. Granjas Coapa, C.P. 14330, México. malixa44@hotmail.com

\& Departamento de Pedagoxía e Didáctica. Facultade de Ciencias da Educación. Universidade de Santiago de Compostela. Campus Vida. Campus Vida. Rúa Prof. Vicente Fráiz Andón, s/n,15782 Santiago de Compostela. España. anton.costa@usc.es
}

Cómo citar este artículo: Civera Cerecedo, Alicia y Antón Costa Rico. «Desde la historia de la educación: educación y mundo». Historia y Memoria de la Educación 7 (2018): 9-45. 
den a reunir rasgos y condiciones similares, a modo de «invariantes ${ }^{1}$ según los momentos históricos, que permitirían establecer alguna tipificación, sin que ello nos lleve a dejar de observar las diferencias y singularidades que entre ellas se pueden reconocer también frecuentemente.

A la hora de abordar la específica problemática que el desarrollo de la formación ha venido encontrando en los escenarios rurales, por lo regular dirijimos nuestras miradas hacia las escuelas, haciendo del binomio formación-escuela el punto clave de observación. Esto ha sido así a lo largo del pasado siglo, en cuanto por otra parte se ha convenido en distinguir en la práctica:

a) los procesos de educación familiar (como primer círculo socializador de las personas),

b) los procesos de inculturación religiosa,

c) aquellos otros ambientales y comunitarios de socialización, situados en el posible ámbito de la llamada cultura popular,

d) y, finalmente, los procesos formativos escolares, dotados éstos de un fuerte y a menudo superior simbolismo.

$\mathrm{Al}$ insistir con nuestra mirada en estos últimos procesos hemos procedido a una simplificación en cuanto a la captación, estudio y comprensión de los posibles alcances, sentidos y significados de la educación en los escenarios rurales. Una simplificación limitativa a la hora de relatar, analizar e interpretar los procesos históricos de cambio social. Sin embargo, y como en otros campos, al comenzar a realizar una mirada alargada, que hace entrar en juego las aportaciones de la sociología, de la antropología cultural o también del discurso político, se han venido a renovar los supuestos, fuentes y orientaciones metodológicas de investigación, haciendo posible la revisión de la anterior simplificación. Por ello, hoy somos conscientes de la limitación que presentaba el centrarse en el estudio de las instituciones escolares (amparadas o propiciadas por las específicas legislaciones) con la intención de explicar adecuadamente la incidencia de la educación en los espacios rurales, aunque sin embargo la historia escolar sigue ocupando la centralidad de los registros de investigación histórica sobre la educación en relación con el mundo rural.

\footnotetext{
${ }^{1}$ Pierre-Louis Gauthier, Odile Luginbühl, «L'éducation en milieu rural: percepcións et realités», Revue Internationale d'éducation de Sèvres, 59 (2012): 35-42.
} 
Siendo indudable su fuerza y centralidad, desde la paulatina constitución decimonónica de los sistemas políticos nacionales, no es menos cierto que las variaciones y desarrollos de alcance educativo, también en los espacios rurales, tienen una directa relación o en casos dependencia de otros factores e instancias no escolares. Y todo esto nos ha traído a este monográfico de Historia y Memoria de la Educación, que hemos titulado «Educación y mundo rural» con la intención de poder «descentrarnos de las escuelas», sin necesidad de renunciar a ellas, para así poder acoger otras muestras de estudio histórico-educativo significativas, mediante las que poder alterar nuestra mirada más usual, de modo que, sobre la lógica de la sospecha, podamos construír un conocimiento crítico y por ello de superior valor comprensivo e interpretativo.

Contexto rural o mundo rural o espacio rural, que son diversos modos de referirnos a una misma cuestión, no son expresiones o categorías acerca de las cuales podamos aceptar una unívoca comprensión. Como otras tantas categorías de la realidad y empiria social, la categoría mundo rural es profundamente situacional e histórica en su definición, lo que, sin embargo, no nos impide alcanzar un acuerdo básico comprensivo. La construcción cultural de lo rural se ha ido armando a partir del desarrollo de su opuesto: lo urbano. La distinción urbano-rural ha clasificado de diferentes maneras a la población que se le asocia, en distintos lugares en la estratificación social y de la propia administración pública; dentro de ésta, lo rural suele ser definido por los censos en términos de densidad poblacional y su asociación a la ocupación en actividades del sector primario, lo cual tiene implicaciones en la asignación de recursos, establecimiento de programas de desarrollo, y muchos otros aspectos. ${ }^{2}$

En términos de análisis sociológico y desde los enfoques funcionalistas y estructuralistas se han apurado los descriptores convencionales, «permaneciendo», en cambio, de un modo más lábil la definición desde la mirada histórica, la antropológica o la lingüística, pero se han ido afi-

\footnotetext{
${ }^{2}$ Alicia Civera, «Los libros sobre la educación rural en México publicados en el nuevo siglo: una revisión general», en.), Historia e historiografia de la educación en México. Hacia un balance 2002-2011, coord. María Esther Aguirre Lora (2016), II, 249-271.
} 
nando las miradas hacia los distintos tipos de ruralidad. ${ }^{3}$ Aquí, nos referiremos al mundo rural como aquel conjunto de escenarios o espacios socio-naturales en los que el contacto físico y emocional de las personas entre si está muy intermediado por la naturaleza, al punto de que sus dedicaciones profesionales tienen en alto porcentaje una directa conexión con la producción agraria-ganadera o marítima, percibiéndose, además, entre ellos manifiestos lazos humanos de carácter comunitario, estando igualmente presentes y siendo comprensibles pautas, ritos y conductas que tienen a la naturaleza no humana como referentes. En palabras de Herminio Almendros desde Cuba y en 1960: «Un grupo humano del campo, por pequeño que sea, es vivo organismo tejido de lazos y motivos de vida social». ${ }^{4}$ Es decir, manejamos una definición souple. Relativamente amplia, pero también enmarcadora con respecto a los rasgos que mejor caracterizan a los espacios urbanos.

Hablamos, pues, de escenarios rurales diversos. Escenarios que han acogido y acogen considerables transformaciones históricas - tanto con su participación como malgré lui- que en la actualidad están en retroceso a escala mundial (se ha producido una implosión de las ruralidades a escala mundial), dados los crecientes índices de concentración humana y urbana, así como los procesos de migración y cambios muy grandes en las formas de explotación de los productos naturales. Escenarios muy vivos y dinámicos en algunos casos en el presente; estructurales y extraordinariamente dominantes en el espacio europeo o americano en otros momentos del pasado. Que han sido viveros de tradiciones históricas y culturales que pautaron la vida de las gentes, pero que muy frecuentemente han perdido esa capacidad en el presente. Que han sido el locus de creativas iniciativas sociales, culturales y educativas en múltiples casos, o que por el contrario fueron el sostén de posiciones ideológicas y axiológicas dogmatizantes. Donde se construyeron algunas de las más inteligentes innovaciones pedagógicas, o desde donde, al contrario, se hicieron o se hacen patentes las manifestaciones de "mal desarrollo» educativo y cultural, específicamente escolar.

\footnotetext{
${ }^{3}$ Alicia Civera, Juan Alfonseca y Carlos Escalante (coords.), Campesinos y escolares. La construcción de la escuela en el campo latinoamericano (siglos XIX y XX) (México: Miguel Ángel Porrúa y El Colegio Mexiquense, 2011).

${ }^{4}$ Herminio Almendros, Carta a un maestro de una escuela rural (La Habana: Ministerio de la Educación, «Publicaciones para maestros», 2 (1960), 18.
} 
Desde la Historia de la Educación se han llevado o se están llevando a cabo distintos modos de observar las posibles interrelaciones entre los procesos educativos y los contextos rurales. Nos referiremos, pues, a algunos de los modos de observar, no tanto para valorar o hacer recuento de las investigaciones ya realizadas, cuanto para apuntar cuestiones, referencias y posiciones susceptibles de ser analizadas o tomadas en consideración con la intención de avanzar en el conocimiento histórico-educativo. En esta dirección quieren situarse de igual modo las aportaciones, que de un modo abierto y de mesa de trabajo, se hacen presentes en este Monográfico.

\section{LA ESCUELA RURAL: CENICIENTA DE LA EDUCACIÓN}

Las escuelas rurales y su problemática, generalmente grave, han sido el asunto que ha centrado la mirada de la Historia de la Educación hacia el mundo rural. Pongamos un ejemplo notable: en 1976 la prestigiosa revista española Cuadernos de Pedagogía, que recién llegaba para acompañar e impulsar la transformación democrática de la educación, editaba un lacerante número con el título «La escuela rural: crónica de una marginación». ${ }^{5}$ Sin embargo y contradictoriamente, un contexto rural, humanamente rico, situado en íntimo contacto con la naturaleza, puede ser de una extraordinaria riqueza, capacidad e intensidad educativa. Comenio, Rousseau, Pestalozzi, el Padre Sarmiento... nos dejaron fecundas reflexiones y advertencias al respecto. En palabras aún de comienzos del siglo XXI lo decía el escritor gallego Ramiro Fonte, recordando su infancia de los pasados años 50, y en todo caso lamentando su pérdida:

As familias que vivían do peixe atesouraban a verdadeira memoria popular de Pontedeume... Analfabetos, manexaban oralmente o fermoso dicionario do mar. Aprendíannos que as embarcacións do peirao se correspondían con distintos nomes, como caiuco, bote ou buceta, e que eran necesarios outros nomes como estrobo, tolete ou rizón para poder navegar nelas. Na súa memoria están trazadas as cartas náuticas da ría de Ares, e gardaban os nomes dos baixos, dos rochedos, das penas, as marcas que tomaban como referencia no litoral para pescar á liña. ${ }^{6}$

\footnotetext{
${ }^{5}$ Cuadernos de Pedagogía, Suplemento n. ${ }^{\circ} 2$ (1976).

${ }^{6}$ Ramiro Fonte, Os meus ollos (Vigo: Edicións Xerais de Galicia, 2004), 48.
} 
Pero, el mundo rural interrelaciona con otros contextos sociales, es decir, con los espacios urbanos, que se han venido manifestando como más dinámicos en cuanto a la intensidad de los cambios sociales, tecnológicos o productivos y en esta medida han venido afirmando su posición invasiva y supremacista sobre los contextos rurales, ocasionando la minusvaloración o la deslegitimación de resortes y manifestaciones culturales y educativas asentadas y denotadas como valiosas en el mundo rural, mientras esa imposición daba a entender lo que deberían ser las nuevas vías de la educación valiosa.

Vías, de todos modos, operadas por lo común con limitada fuerza y presencia en el mundo rural. Es desde esta consideración desde la que se puede hablar de la educación y de la escuela en el mundo rural como la «Cenicienta de la educación. Con su oferta de una educación casi siempre empobrecida, al tiempo de provocar un negativo «desconocimiento» de los referentes culturales y educativos de proximidad entre aquellos a quienes pretende educar. En cierto modo, ha sido «la escuela» contra la «civilización rural», casi siempre una escuela "para» la gente del campo, y no una escuela «de» la gente del campo. ${ }^{7}$ De nuevo, en palabras de Herminio Almendros, escritas desde Cuba en los momentos en que se abrían las posibilidades de poner en marcha nuevas escuelas: "Las escuelas rurales han formado a los alumnos con objetivos y normas de una educación bastarda, desvitalizada, sin raíz y sin nervio; y ese hecho desdichado no debe continuar». ${ }^{8}$

La escuela rural destinada a los hijos de los campesinos o de los marineros se tuvo que enfrentar a grandes dificultades: la «Cenicienta de la educación», ${ }^{9} \sin$ importar a los sectores sociales más poderosos, aunque ellas representaron —en muchos pueblos y aldeas- uno de los lugares de aculturación, que solo alcanzaron a llevarla a efecto de una forma pobre. En la actualidad somos conscientes de este mal desarrollo de la

\footnotetext{
${ }^{7}$ Alicia Civera, «Range and limits of rural school historiography in Latin America: 19th and 20th Centuries. Some Reflections», en Connecting Histories of Education: Transnational and Cross-Cultural Exchanges in (Post)Colonial Education, eds. Barnita Bagchi, Eckhardt Fuchs and Kate Rousmaniere (Oxford: Berghahn Books, 2014).

${ }^{8}$ Almendros, Carta a un maestro, 4.

${ }^{9}$ Sobre la cuestión se extiende Luca Montecchi en su aún reciente texto I contadini a scuola. La scuola rurale in Italia dall'Unità alla caduta del fascismo, (Macerata: EUM - Edizioni Università di Macerata, 2015), reseñado en este mismo número de la revista.
} 
escuela en el común de los escenarios rurales. Conscientes de sus tantas limitaciones de todo tipo. De las dificultades, frecuentemente gravísimas, sufridas por los niños y niñas en cuanto escolares. De las sufridas por las familias. De las del magisterio, agravadas en el caso de las maestras. Al caso, viene bien recordar la Lettera a una professoresa que los alumnos de Barbiana junto con Don Milani escriben en los pasados años sesenta desde Italia, en donde se contraponen las penalidades y la cultura burguesa a una educación emancipadora.

O recordar, también, la extrema humildad de tantas escuelas españolas, como reflejaron las preocupadas llamadas de atención realizadas por Luís Bello en los pasados años veinte a través de sus crónicas de «Viajes de escuelas», reeditadas por el profesor Agustín Escolano en los pasados anos noventa, que trazaban certeras fotografías aún visibles décadas más tarde en el tiempo oscuro del "nacional-catolicismo», como quedó de relieve en aquel libro titulado Escuelas, pueblos y barrios (Antropología educativa) ${ }^{10}$ de 1980 o, como ejemplo, en el estudio de Oscar Rodríguez en relación con la provincia de Almería en Andalucía. ${ }^{11}$ Penurias de una escuela que igualmente han sido valoradas en estudios muy diversos, de la mano de investigadores como Narciso de Gabriel, Vicente Peña Saavedra, José María Hernández, ${ }^{12}$ José Antonio Caride, ${ }^{13}$ Miguel Grande, Carmena Regidor, Marina Subirats ${ }^{14}$ o más recientemente también por parte de Lacruz Alcocer ${ }^{15}$ y de Prieto Ortega. ${ }^{16}$

\footnotetext{
${ }^{10}$ Mary Knipmeyer, Marta González Bueno, Teresa San Roman, Escuelas, pueblos y barrios. Antropología educativa) (Madrid: Akal,1980).

${ }^{11}$ Oscar Rodríguez Barreira, Pupitres vacíos. La escuela rural de la postguerra. Almería, 1939-1953 (Almería: Instituto de Estudios Almerienses, 2015).

${ }^{12}$ Mediante investigaciones sobre la historia de las escuelas rurales en Galicia en los dos primeros casos y en Castilla-León, en el caso de Hernández Díaz.

${ }^{13}$ Con estudios sobre la grave problemática sociológica y cultural vivida alrededor de las escuelas rurales en los pasados años setenta y primeros ochenta, de lo que también quedó una notable constancia en el n. ${ }^{\circ} 3$ de la Revista Galega de Educación (1986), impulsada por el movimiento de renovación pedagógica Nova Escola Galega.

${ }^{14}$ Debiendo destacar: Miguel Grande, La escuela rural: situación educativa en el medio castellano-leonés (Granada: Editorial Popular, 1981); Gregoria Carmena y R. Regidor, La escuela en el medio rural (Madrid: Ministerio de Educación y Ciencia, 1984); Marina Subirats, L'escola rural a Catalunya (Barcelona: Rosa Sensat/Edicions 62).

${ }^{15}$ Miguel Lacruz Alcocer, Entre surcos y pupitres. Historia de la educación agraria en la España de Franco (Madrid: Endymion, 1997); Miguel Lacruz Alcocer, «Aulas entre rastrojos», Revista de Educación, 322 (2000):11-27

${ }^{16}$ Miguel Ángel Prieto Ortega, La pariente pobre (Significante y significados de la escuela rural) (Madrid: MEC/CIDE, 1995).
} 
El final de la etapa franquista en España y la necesidad de luchar por el derecho a la educación condujo a una renovada «campaña» de llamadas de atención, que propició la publicación Cuadernos de Pedagogía, por medio de la cual y a lo largo de la década 1975-1985 afloraron frecuentes estudios y referencias sobre el asunto; Jesús Jiménez, en 1988, a todos nos recordaba que «los pueblos también existen» después de haber situado la cuestión en los siguientes términos: «La escuela rural: entre el olvido y la esperanza», con el trasfondo que en 1983 habían trazado Fabricio Caivano y Jaume Carbonell, motores intelectuales de la publicación, quienes habían señalado las coordenadas: «Escuelas, cultura, territorio».

Esta penuria y estas preocupaciones también las habían denunciado Bernard Grosperrin y Michel Froeschlé en relación con la escuela rural francesa, aunque en un tiempo anterior. ${ }^{17} \mathrm{O}$ el profesor Pierre Furter, desde sus penetrantes análisis a la hora de referirse a las escuelas suizas y a lo que llamó el maldeveloppement educativo de la región del Jurà, llamando la atención sobre las conexiones sistémicas entre lo que ocurre en el sector educativo y los reflejos que se pueden apreciar en otros componentes del territorio y de las comunidades locales y rurales, que también muestran el maldeveloppement, al tiempo de insertar estas precisas reflexiones en un escenario comparativo internacional. ${ }^{18}$ Los posibles cuadros problemáticos en relación con todo esto son, como sabemos, muy numerosos en tantos países y estados de toda Europa y de América; y que decir de tantas realidades asiáticas, africanas ${ }^{19}$ que en ocasiones percibimos a través de imágenes fílmicas, como en el caso de Ni uno menos de Zang Yimou de 1999, o en Le chemin de l'école, de Pascal Plison, de 2013. Son, también numerosos los estudios que aquí o allá han anali-

\footnotetext{
${ }^{17}$ Bernand Grosperrin, Les petites ecoles sur l'Ancien Regime (Rennes: Ouest France, 1984); Michel Froeschlé, L'école au village: les petites écoles de l'Ancien Régime à Jules Ferry (Nice: Serre, 2007).

${ }^{18}$ Pierre Furter, La problematique de la formation et de la scolarisation dans les espaces de montaigne. Une perspectiva internationale (Documento de Seminario, Santiago de Compostela, mayo, 1990). Pierre Furter, Os sistemas de formaçâo em seus contextos. Introduçâo a um metodo de educaçâo comparada (Rio de Janeiro: Editora da Fundaçâo Getulio Vargas, 1982). Pierre Furter, Les espaces de la formation. Essai de microcomparaison et de microplenfication. (Lausanne: Presses Polytechniques Romandes, 1983).

${ }^{19}$ FAO, UNESCO CIDE, Educación para la población rural en Brasil, Chile, Colombia, Honduras, México, Paraguay y Perú (Roma: FAO, 2004); Juan Carmelo García, «El estado de la educación rural en América Latina y en África», Revista de Educación, 322, (2000): 119-142; Gérard Vigner et al., "Scolarisation et monde rural: dossier», Diagonales, 37 (1996): 14-35; Vittoria Cavicchioni y Anna Erikson, Urban and rural school: special survey on primary education (París: UNESCO, 1992).
} 
zado la problemática del éxodo rural, la reducción de la natalidad y el envejecimiento global de las poblaciones situadas en los hábitats rurales, ${ }^{20}$ como elementos que empobrecen la dimensión educacional presente en un entorno humano cualificado y entorpecen el mantenimiento de centros escolares, con sus mayores costes económicos de funcionamiento.

\section{EDUCACIÓN Y DESARROLLO EN MEDIOS RURALES}

Pero también debemos referirnos a otras representaciones de la escuela rural más allá de ésta que la ve sólo como la escuela urbana pero empobrecida. Algunos estudios en Chile muestran como los procesos de escolarización en las zonas rurales tienen diversos desarrollos y resultados según las características de los procesos de producción agrícola, o el régimen político como muestran los índices de alfabetización y escolaridad en Cuba. Durante la primera mitad del siglo Xx se desarrollaron muchas experiencias educativas en los medios rurales en todo el mundo, que en el caso de América Latina se pensaron como programas e instituciones especialmente pensadas para el campo, es decir, con un espíritu ruralista que ligaba lo educativo a las necesidades de desarrollo en los medios rurales. En Brasil como en Bolivia desde principios de siglo, la presencia de instituciones educativas en el campo buscaba frenar el éxodo a las ciudades; en estos y otros países como Argentina el proyecto modernizador de la escuela tuvo como motor el desarrollo de la agricultura de exportación, mientras que en México «la educación rural» desarrollada después de la Revolución buscaba colocar a la escuela en el centro del desarrollo de las comunidades rurales en el contexto de la reforma agraria y la construcción de un Estado que buscaba desplazar el poder de la Iglesia. Pedagogías similares, apropiadas con distintas particularidades, sirvieron para el apoyo de regímenes democráticos o dictatoriales (como en el caso de Trujillo en Santo Domingo), y fueron desplegados por distintos sujetos sociales como los lasallistas en el sur de Brasil, el gobier-

\footnotetext{
${ }^{20}$ En el caso español no podríamos dejar de citar algunas muy destacadas referencias: Víctor Pérez Díaz, Emigración y cambio social: procesos migratorios y vida rural en Castilla (Barcelona: Ariel, 1971); Luis A. Camarero, Del éxodo rural y del éxodo urbano: ocaso y renacimiento de los asentamientos rurales en España (Madrid: Ministerio de Agricultura y Pesca, 1993); Carlos Serrano Lacarra, Despoblación y territorio (Zaragoza: Centro de estudios sobre la despoblación y desarrollo de áreas rurales, 2007), o también la literaria y reciente de Sergio del Molino, La España vacía. Viaje por un país que nunca fue (Madrid: Turner, 2016).
} 
no federal en México, los grupos indígenas en Bolivia o los trabajadores agrícolas anarquistas en Argentina. ${ }^{21}$

Una amplia bibliografía muestra, entre otras cosas, los diferentes resultados de estas experiencias, las resistencias culturales y las negociaciones que estos proyectos tuvieron en su intento por entrar a un mundo rural con sus propias instituciones socializadoras, las formas en que los pobladores les dieron un sentido y las modificaron. ${ }^{22}$

Este tipo de proyectos ruralistas desplegados en América Latina, junto con otro similares armados en varios países como China y Turquía, o para población específica como los exesclavos en Estados Unidos constituyeron la base de una serie de políticas que tuvieron el deseo de que la escuela dejara de ser la «cenicienta» tradicional, para ser en cambio una preciosa mediación al servicio del desarrollo local. Hacia ahí se encaminaron los primeros proyectos piloto de la UNESCO desde su nacimiento y su formalización en la «Educación fundamental». La UNESCO uniría la enseñanza de elementos fundamentales como la lectura, la escritura y las operaciones básicas con la capacitación para el trabajo en proyectos educativos que englobaban a la población infantil y adulta, es decir, a toda la población en su conjunto, con proyectos económicos específi$\cos ^{23}$

Los empeños en enlazar educación rural y desarrollo económico se sostuvieron por décadas. Una general llamada de atención se hizo desde la UNESCO en 1975 con su informe La educación en el medio rural, que profundizaba las Recomendaciones aprobadas en las Conferencias de educación convocadas por el Bureau International de l’Éducation en

\footnotetext{
${ }^{21}$ Véanse por ejemplo los trabajos incluidos en Civera, Alfonseca y Escalante (coords.), Campesinos y escolares. La construcción de la escuela en el campo latinoamericano (siglos XIX y XX), y en Lucía Lionetti, Alicia Civera y Flávia Obino Correa Werle (comps.) Sujetos, comunidades rurales y culturas escolares en América Latina (Argentina: Editorial Pro-historia-El Colegio de Michoacán y El Colegio Mexiquense, 2013).

${ }^{22}$ Entre otros véase Pilar Gonzalbo y Gabriela Ossenbach (coords.), Educación rural e indígena en Iberoamérica (México: El Colegio de México y UNED, 1999); Flávia Obino Correa Weerle (coord.) Educação rural em perspectiva internacional. Instituções, prácticas e formação do professor (Ijuí: Universidade Regional do Noroeste do Estado do Rio Grande do Sul, 2007); y Teresa González y Oresta López (coords.) Educación rural en Iberoamérica. Experiencia Histórica y construcción de sentido (España: Anroat, 2009).

${ }^{23}$ Alicia Civera, «Entre lo local y lo global. La Unesco y el proyecto educativo piloto de México 19471951», Annali di storia dell'educazione, 22 (2015):166-179.
} 
1936 y 1958 a propósito de la organización de la enseñanza rural y de las posibilidades de acceso a la educación en estos espacios, respectivamente; una llamada que prosiguió con los informes de Pierre Rakotomalla y de Le Thanh Khoi, L'éducation au milieu rural (París, 1974) y de Louis Malassis, Ruralidad, Educación y Desarrollo (París, 1975). La Conferencia Mundial convocada en 1979 por las Naciones Unidas sobre la reforma agraria y el desarrollo rural vino a afirmar, por su parte, la virtualidad del desarrollo rural integrado.

Desde América Latina, desde la CEPAL, en conjunción con la UNESCO, Carlos A. Borsotti presentaba en 1984 un informe general, Sociedad rural, educación y escuela en América latina, ${ }^{24}$ en donde se reclama ese desarrollo rural integrado. Erik Raymaerkers y Myriam Bacquelaine formulaban la necesidad de «una educación integrada de base para el desarrollo rural» ${ }^{25}$ como un modelo educativo que se inspira en los valores endógenos; que toma en cuenta las resistencias al cambio y que saca partido de los resortes psicosociológicos, las aptitudes y los conocimientos capaces de estimular el desarrollo; con contenidos apoyados en las características ambientales, capaz para transmitir un saber eficaz y funcional para las comunidades locales, en la lengua que contiene la experiencia vivida y en el contexto participativo del desarrollo comunitario.

En esta dirección comenzaron a moverse distintos estudios y propuestas de experimentación desarrolladas en variados lugares y países, a menudo con algún apoyo institucional, procedente en ocasiones de los propios Organismos Internacionales, dándose cuenta de sus resultados en revistas y textos de alcance internacional ${ }^{26} \mathrm{o}$ en la International Encyclopedia of Education. ${ }^{27}$

\footnotetext{
${ }^{24}$ Carlos A. Borsotti, Sociedad rural, educación y escuela en América latina (Buenos Aires: Kapeluz, 1984).

${ }^{25}$ Erik Raymaerkers y Myriam Bacquelaine, «Una educación integrada de base para el desarrollo rural», Perspectivas, 3 (1985): 487-502.

${ }^{26}$ Sean como ejemplo, Lynn Ilon and Peter Moock, «School atributes, house hold characteristics, and demand for schooling: a case study of rural Peru", International review of education, 4 (1991): 429-451; o Wasantha Ekanayake, «La pédagogie en zone rurale: comment promouvoir le développement rual à la base», Perspectives, 1 (1990):129-143, para el caso de Sri Lanka. También, Manzoor Ahmed, Phillip Coombs, Education for rural development. Case Studies for Planners (New York: Praeger, 1975).

${ }^{27}$ Amos Dreyfus, «Agricultural and Rural Education», en The International Encyclopedia of Education, eds. Torsten Husen y Neville Postlethwaite (Oxford: Pergamon, 1994), 240-244.
} 
Durante la segunda mitad del siglo las experiencias que enlazaban educación rural y desarrollo fueron modificando sus estrategias en una mayor conjunción con los intereses de la agronomía de exportación. En el caso de América Latina, la fundación Rockefeller jugaría un papel importantísimo en la generación de instituciones educativas ligadas a la capacitación técnica para el trabajo y procesos de modernización, colocando a los jóvenes en un primer plano a partir de los clubes $4 \mathrm{X} 4 \mathrm{y}$ sus variedades en distintos países. Para principios del siglo XXI, viejas y nuevas formas se han implementado a raíz del crecimiento de las agroindustrias y de las nuevas técnicas de explotación de la tierra: los maestros itinerantes, las misiones pedagógicas o culturales, la concentración de escuelas, los ciclos alternados y otros.

Todos estos programas de educación "para» la población de medios rurales, han convivido y/o competido con otros proyectos educativos o pedagógicos menos visibles pero no menos importantes. En América Latina, con la educación indigenista e indígena por ejemplo, pero también con proyectos educativos construidos no "para» la población rural, sino «por» la población rural o más bien, por sujetos internos en la vida rural. En este caso podemos mencionar, por ejemplo, la Educaçâo do campo en Brasil, ${ }^{28}$ diversas experiencias de educación intercultural o las experiencias educativas que arman los grupos indígenas desde la autonomía local, como en Chiapas y otros estados de México. Como hemos visto y se podrá apreciar en los artículos incluidos en este Monográfico, la interrelaciones entre pedagogía, política, economía y cultura en los medios rurales es de una gran complejidad.

\section{¿LA ESCUELA RURAL, EN LA VANGUARDIA DE LA EDUCACIÓN?}

La imagen de la escuela rural como «cenicienta», aunque adecuada, no da cuenta de toda la vida educativa desarrollada en el pasado en estos contextos. Como decíamos, también en ellos o incluso específicamente desde ellos se han desarrollado iniciativas singulares en el campo educativo y los estudios de Historia de la Educación son conscientes de esto. La ruralidad se hace presente en la escuela y transforma y crea proyectos

\footnotetext{
${ }^{28}$ Véase por ejemplo María Antonia de Souza, «La Educación del Campo y la experiencia colectiva de los movimientos sociales: Indagando sobre la Educación Rural en Brasil», en Lionetti, Civera y Werle (comps.) Sujetos, comunidades rurales y culturas escolares en América Latina.
} 
pedagógicos. Podemos imaginar los días y los empeños de Pestalozzi y de los filantropistas. Sabemos que sus ejemplos tuvieron ecos diversos a lo largo del XIX y en los escenarios rurales, si bien parece del caso que vengamos hacia el tiempo de la Escuela Nueva y su énfasis en los educandos, cuando las administraciones públicas se deciden a crear escuelas en los campos, a donde comenzarán a llegar jóvenes maestros y maestras o misioneros que en diversos casos arriban con inquietudes de transformación cultural, al tiempo que comienza a percibirse la presencia intermitente de otros actores culturales, sea a través del catolicismo social, de los impulsos masónicos, de los nacientes sindicatos, o la formación d elos propios jóvenes de los medios rurales.

No olvidemos que las escuelas unitarias - tuvieron ocasión de escribir Francisco Larroyo y Domingo Tirado Benedi en 1961 - han permitido las realizaciones de métodos y técnicas que luego han sido utilizados en toda clase de escuelas. En una escuela de este tipo surgió el famoso Plan Labotario Dalton, de Ellen Parkhurst, que tanta aceptación tuvo hace varios años en los países de habla inglesa. Los ensayos y técnicas de las cooperativas llevados a cabo por Profit en Francia se realizaron en gran parte en escuelitas unitarias. La celebre técnica de la imprenta en la escuela fue ensayada por Freinet en una escuela de aldea. El sistema de trabajo por equipos, que con tanto éxito ha extendido el inspector escolar francés Roger Cousinet, se ha aplicado y se aplica, con mayores posibilidades que en cualquiera otra parte, en las escuelas unitarias. ${ }^{29}$

En efecto. Desde la escuela de Jasnaia Poliana impulsada por Tolstoi, pasando por las escuelas secundarias populares danesas Grundtvig, hasta la escuela montessoriana de La Montesca de Città di Castelo (Perugia), en las escuelas rurales se produjeron innovaciones de alguna trascendencia; las reformas curriculares propiciadas por Lombardo Radice en Italia hicieron de algunas de las escuelas rurales focos de irradiación renovadora, y otro tanto ocurrió en otras latitudes europeas. El orfanato de Cempuis, bajo la guía de Paul Robin con su perspectiva de educación

\footnotetext{
${ }^{29}$ Luis Fortunato Iglesias, Aprendizaje vivencial de la lectura y la escritura (Buenos Aires: Ediciones Pedagógicas, 1987), 19.
} 
integral, se desarrolló igualmente en un escenario rural, y tuvo marcada influencia sobre otras experiencias educativas libertarias. Es oportuno recordar las escuelas-hogares campestres de Hermann Litz, como la de Haubinda en Turingia, o también las Comunidades escolares libres como Odenvaldschule de Paul Geheeb, cerca de Heildelbeg, en aquel tiempo luminoso que fue la República de Weimar finalizada la Primera Guerra Mundial, si bien no estamos en estos casos ante escuelas rurales para hijos de campesinos, ni tampoco siempre son los ideales de humanidad y de progreso las que las mueven en todas las ocasiones:

La misma escuela es una aldea en miniatura con sus establos, graneros y cobertizo de herramientas situados frente por frente del patio en que juegan y corretean los niños [...]. Al igual que los campesinos, celebran los escolares sus fiestas de tiempo de cosecha; es la época en que se suspenden las clases y marcha todo el mundo al campo para recolectar el heno o las patatas. Las diversas estaciones del año tienen para los escolares las mismas características que para los habitantes de la aldea y las cosas que interesan a los unos y a los otros son practicamente las mismas. ${ }^{30}$

La huella de lo que preconiza la Escuela Nueva podremos localizarla a lo largo y ancho de la geografía internacional. En particular si aludimos a la metodología decroliana de los centros de interés que ya se percibía aquí ${ }^{31}$ y allá en los años veinte, entremezclada con la apelación deweyiana a la experiencia y a los proyectos: no es así de extrañar el eco que pronto en Europa recibe, entre otros títulos, Schools of Tomorrow (1915) de Evelyn y John Dewey, en donde se muestran varias experiencias escolares rurales estadounidenses. A mediados de los años 30 la Revista de Pedagogía, bajo la atenta dirección de Lorenzo Luzuriaga, daba a conocer distintas experiencias de «nueva escuela rural» que tenían lugar en variadas geografías rurales españolas. ${ }^{32}$ Ocurría en los momentos en que

\footnotetext{
${ }^{30}$ Thomas Alexander, Beryl Parker, La Nueva Educación en la República Alemana (Madrid: Aguilar, 1931), 246-247.

${ }^{31}$ María del Mar del Pozo Andrés, «Desde l’Hermitage a la escuela rural española: introducción, difusión y apropiación de los "centros de interés" decrolianos (1907-1936)», Revista de Educación, Número extraordinario (2007): 143-166.

32 Antón Costa Rico, «Escolas en contornas rurais en Galicia: horizonte dificil/ horizonte posible», Innovación Educativa, 24 (2014): 133-153.
} 
la «siembra de renovación» llevada a cabo por Célestin Freinet comenzaba a ser el cañamazo que vitalizaba pequeñas escuelas rurales, ${ }^{33}$ y no nos olvidaremos aquí del «laboratorio» en que se había convertido $L e$ Pioulier en Vence, que será "presentado» en 1949 mediante el film L'école buisonniére de Jean-Paul le Chanois («La escuela que va a la aventura»). Varios de aquellos maestros freinetianos trasladarían la simiente a América y así vemos, entre otros, a José de Tapia y Bujalance en su nueva escuela rural freinetiana de San Andrés de Tuxtla (Veracruz, México). ${ }^{34}$ Distintos idearios, propuestas pedagógicas, instituciones y técnicas tuvieron elaboraciones originales en las áreas rurales, como la educación racionalista de Ferrer y Guardia en zonas rurales del Atlántico en México. La «educación rural mexicana» desde la década de 1920 combinaba de una manera ecléctica propuestas de la Escuela Nueva, especialmente de Dewey con la educación soviética. Instituciones no necesariamente escolares, como las misiones pedagógicas y educativas de España, Chile, México, Uruguay y Brasil tuvieron un auge especial en las zonas rurales y a partir de su éxito se trasladaron y adecuaron a las áreas urbanas. ${ }^{35}$ Las interconexiones entre distintas ideas y experiencias pedagógicas y sus influencias recíprocas son un campo aún por explorar en la Historia de la Educación. La literatura existente sugiere que las influencias tuvieron múltiples direcciones, y no solo de lo urbano hacia lo rural y de Europa hacia otras regiones. ${ }^{36}$

Un grave interrogante ha gravitado casi constantemente en torno a la educación rural: preparar a sus alumnos con intensidad para una «mejor vida rural» como horizonte o con un sentido más amplio; en palabras del sociólogo Julio Carabaña: «¿Tiene la escuela rural que formar alumnos

\footnotetext{
${ }^{33}$ Como meros ejemplos, José M. Fernández Soria y María del Carmen Agulló Díaz, Una escuela rural republicana (Valencia: Universidad de Valencia, 2004); Salomó Marqués Sureda (ed.), Un poble, una escola, una revista: la revista Inquitud de l'escola de Menàrguens (Lleida, Ajuntament de Menàrguens, 2010).

${ }^{34}$ Fernando Jiménez Mier Terán, Un maestro singular: vida, pensamientro y obra de José de Tapia (México: Jiménez Mier, 1996).

${ }^{35}$ Véase los trabajos incluídos en Laura Giraudo (coord.), Anuario de Estudios Americanos, 67 (2), (2010).

${ }^{36}$ Véase por ejemplo Claudia Gerdenitsch y Johanna Hopfner (eds.), Erziehung und bildung in lândlichen regionen, (Peter Lang, Austria, 2010); Bagchi, Fuchs y Rousmaniere (eds.), Connecting Histories of Education: Transnational and Cross-Cultural Exchanges in (Post)Colonial Education, eds. Barnita Bagchi, Eckhardt Fuchs and Kate Rousmaniere (Oxford: Berghahn Books, 2014).
} 
rurales?». ${ }^{37}$ Las respuestas fueron contrapuestas. Así, hubo docentes y sectores de opinión, de orientación conservadora, que se inclinaron a favor de una respuesta favorable:

En la escuela rural existen motivaciones de especialización, derivadas de las labores del campo: el niño en la escuela activa rural tiene que vivir una especie de preaprendizaje de las labores campesinas, así como en las escuelas ciudadanas tiene que vivir una preparación de lo que será, más tarde, su vida en la ciudad, ${ }^{38}$

decía un destacado profesor que preconizaba en España el activismo escolar a mediados de los años 30, aunque no era esta la opinión de alguien como Lorenzo Luzuriaga, situado con otra óptica en el mismo espacio de la escuela activa, al preguntarse (traducimos de la edición portuguesa):

¿Debe haber diferencia entre la educación de la juventud rural y la de la juventud urbana?; el problema es muy complejo [pero] podemos adelantar aquí que las diferencias entre uno y otro tipo de educación deben ser apenas accidentales y que, en lo esencial, la educación debe ser la misma. ${ }^{39}$

A partir de los últimos años cuarenta desde la UNESCO se levantarían voces, entre ellas la de Jaime Torres Bodet, Secretario General del organismo en 1948, pugnando por una educación común, sin diferenciaciones regionales, apelando al derecho de todos a la educación ${ }^{40}$ y este fue en adelante el planteamiento promovido en los diversos documentos y recomendaciones de la UNESCO que han aludido a la cuestión, en el sentido de no considerar la educación en las zonas rurales de modo independiente con respecto a los distintos sistemas nacionales de educación, sin menoscabo de la consideración de diferentes orientaciones y centros de interés de acuerdo con el espacio contextual.

\footnotetext{
${ }^{37}$ Julio Carabaña, «¿Tiene la escuela rural que formar alumnos rurales?», Revista de Estudios de la Juventud, (18): 37-45.

${ }^{38}$ J.P.C., Profesor, La Escuela Activa («Colección Biblioteca de Pedagogía Moderna», Gerona: Dalmau Carles Pla Editores, 1933).

${ }^{39}$ Lorenzo Luzuriaga, Pedagogia social e política (Sâo Paulo: Companhia Editora Nacional, 1960): 76-77.

${ }^{40}$ Jaime Torres Bodet, Discurso de la Unesco (México: SEP, 1987).
} 
Para una nueva escuela rural —no solo- pensó Freinet en 1945 su fundamental texto L'Ecole Moderne Française (traducida entre nosotros como Por una escuela del pueblo). Una nueva escuela rural era lo que con anterioridad ya llevaba a cabo Jesualdo con los niños uruguayos de Canteras de Riachuelo, o lo que hacía Sujomlinski en la ucraniana escuela rural de Pávlish, ${ }^{41}$ lo que Avelino Pousa promovía en la escuela de Barreiros (Sarria, Galicia), lo que Mario Lodi nos dejó escrito en Il paese svagliatto sobre sus experiencias en Vho de Piadena, ${ }^{42}$ o el modo de hacer de Luis Fortunato Iglesias en su escuela argentina de Tristán Suárez:

La escuela era clase, taller y comunidad: Era clase: en el aula o fuera de ella se enseñaba y se aprendía, se investigaba en los textos y se leía en libros y revistas y también en las cosas vivas y muertas y en todo material utilizable [...] Era taller de enseñar y aprender haciendo: artes, oficios, artesanías, creatividad de juguetes, herramientas, inventos [...] y era comunidad, natural y viva, dentro y fuera de la escuela [...]; no hay clase, taller ni escuela si no hay comunidad escolar, sin cohesión de sentimientos, de intereses, de ayudas mutuas. ${ }^{43}$

La escuelita era bella en su pobreza y era la escuelita de la alegría, a donde iban naturalmente - querían ir, incontenibleslos humildísimos niños campesinos de la zona, que no obstante estaban ya bien curtidos por rudos trabajos de sol a sol. La escuela era, sin duda, una casita imantada. Tenía rudimentariamente, improvisadamente, todo cuanto ambiciona, reclama y necesita un niño en cualquier lugar de la tierra para crecer y ser feliz. Todos los instrumentos dignos que hacen posible la alegría, desde los goces callados y mudos, hastas los estallidos de júbilo. Y el propio trabajo escolar, dentro y fuera del aula, era la misma alegría. Con ella, abiertos todos los caminos del cuento, el canto, el color, los juegos. Con ella la amistad compartida, la comprensión y los descubrimientos milagrosos de la comunidad viva, sin va-

\footnotetext{
${ }^{41}$ Sumjomlinki, Pensamiento pedagógico (Moscú: Ediciones Progreso, 1975).

${ }^{42}$ Mario Lodi, El país errado (Barcelona: Laia, 1975).

${ }^{43}$ Luis Fortunato Iglesias, «En la escuela no se enseña a estudiar sino se enseña a pensar», Novedades educativas, 26 (1992): 3. Sobre la figura de este profesor, Antón Costa Rico, «Luis F. Iglesias (19152010), pedagogo latinoamericano, Galicia e Nova Escola Galega, con Jesualdo ao fondo», Innovación Educativa, 26 (2016): 305-321.
} 
llas, ni miedos, ni prohibiciones caprichosas, ni rechazos diferenciados por edades, medios, modos de vivir. Ellos iban a la escuela normalmente, ansiosos de vivir sus días, confiados y abiertos. ${ }^{44}$

Con más actualidad, podemos referirnos a lo aprobado en Cuba en 1959 en el «Congreso nacional de Maestros Rurales»: un antecedente de lo que luego serían las "escuelas en el campo", ${ }^{45}$ un ejemplo magnífico de conexión entre la educación escolar, la educación social y las comunidades rurales:

la vida del niño en la visa de la comunidad como base y raíz del trabajo escolar [...] es la cantera real y la única auténtica en la que han de hallarse el origen y el apoyo de la actividad docente [...]; el lenguaje y el cálculo (que son básicos) tiene que partir de la experiencia vivida y se desarrolla siempre con más razón y más seguridad cuando tiene su raíz en la vida. El conocimiento que se va construyendo en cada indivíduo es conocimiento de él y de su mundo; de un mundo que se vs ampliando desde el ámbito familiar y local, que es la auténtica realidad primera. ${ }^{46}$

Y seguimos hablando de «escuelas de vanguardia»: la Escola da Ponte en Vila das Aves y Sâo Tomé de Negrelos en Portugal desde 1976 con José Pacheco y luego con Ademar Ferreira; la escuela extremeña de Fregenal de la Sierra; ${ }^{47}$ la «ciudad de muchachos Bemposta», una singular república de adolescentes y jóvenes en tierras de Galicia procedentes del mundo campesino, hoy desaparecida; las "escuelas campesinas de Ávila»; ${ }^{48}$ la "Casa Santiago n. ${ }^{\circ} 1 »$, situada en Salamanca o lo que fue la «residencia juvenil A Lareira", situada en Santiago de Compostela, en ambos casos siguiendo las orientaciones pedagógicas milanianas; una parte de las Ca-

\footnotetext{
${ }^{44}$ Luis Fortunato Iglesias, «Carta confidencial de agradecimiento a los docentes de E. Echevarría». Copia. Documentación particular.

${ }^{45}$ Oficina Internacional de Educación, La Escuela Secundaria Básica en el Campo: una innovación educativa en Cuba. (París: UNESCO, 1974), 22.

${ }^{46}$ Almendros, Carta a un maestro, 17.

${ }^{47}$ María Josefa Martín Luengo, Fregenal de la Sierra: una experiencia de escuela en libertad (Madrid: Campo Abierto, 1978).

${ }^{48}$ Andrés Aganzo (coord.), Escuelas Campesinas: una experiencia que camina (Madrid: Cares, 1983), y Tomás Diaz, «Escuelas Campesinas de Ávila: animación socio-cultural en el medio rural», Revista de Estudios de Juventud, 18 (1985): 195-210.
} 
sas Familiares Rurales; tantas magníficas experiencias de escuelas rurales alimentadas por la pedagogía Freinet en la Francia rural, en Brasil, en la África francófona o las experiencias de educación infantil que recogía un informe oficial del Ministerio español de Educación en 1990. ${ }^{49}$

Una parte no menor de estas referencias no ha merecido aún el preciso estudio histórico-educativo. En otros casos se hizo sobre todo desde una historia de las ideas y de las instituciones pedagógicas, más que desde la más lograda historia socio-cultural y del currículum. Por otra parte, la interrogante entre educación ruralista o educación común para todos, es un tema aún por tratar por la Historia de la Educación. El debate no ha sido sólo pedagógico, ni se ha limitado a las autoridades de los organismos internacionales o los responsables de la educación pública. En él han estado presentes los intereses de la industria agrícola así como las de los propios «destinatarios» y actores de la escuela rural, quienes han tenido sus propias visiones acerca de sus derechos y de las orientaciones y formas de operar de las instituciones educativas. Un debate que se ha hecho más complejo con el crecimiento y jerarquización de los sistemas educativos y aún más, recientemente, con los propios cuestionamientos acerca del papel de la escuela en la sociedad de la información y la multiculturalidad.

\section{LA ORGANIZACIÓN ESCOLAR UNITARIA EN CONTEXTOS RURALES Y SUS ÁNGULOS POLÍTICOS}

Nos referimos en la mayoría de las ocasiones a escuelas de maestro único o, en todo caso, a escuelas en las que un maestro o maestra atendía a un grupo de alumnos que durante varios cursos escolares y desde el inicio de su escolaridad se interrelacionaban entre si y de modo continuo con una misma figura docente. La organización de los contenidos de conocimiento y su distribución a lo largo del curso, de la planificación de las jornada diaria o de los ciclos semanales y mensuales, la distribución del alumnado en las distintas secciones o grados, la combinación entre la atención individualizada con la atención grupal..., todo ello en términos de microcosmos, ha supuesto, como sabemos, una notable literatura pedagógica (la organización de los dispositivos) desde las primeras dé-

\footnotetext{
${ }^{49}$ Ministerio de Educación y Ciencia, La educación infantil en el medio rural (Madrid, 1990).
} 
cadas del siglo XIX: normas administrativas, legislaciones y la edición de compendios de orientación para docentes, examinados con una relativa atención desde la Historia de la Educación, a lo largo de las más recientes décadas. Para el caso español, sin olvidarnos de las imprescindibles referencias decimonónicas hispanas a Alcántara García y a los textos de Carderera y siguiendo por los de Rufino Blanco o de Solana, podríamos señalar también: las indicaciones presentes en la Revista de Escuelas Normales de los pasados años 20-30 y textos de amplia disfusión como La escuela unitaria de Fernando Sainz (1931), Organización de la escuela unitaria de Adolfo Maíllo (1935), La escuela rural española de Serrano de Haro (1941), la Guía para las escuelas de un solo maestro del CEDODEP (Madrid, 1967), o La escuela unitaria completa del profesor exiliado Santiago Hernández Ruíz (1961), antes de que se decidiese emprender desde el Ministerio de Educació. la ruta de la graduación escolar y de las llamadas concentraciones escolares sobre la base de la Ley General de Educación de 1970, ${ }^{50}$ o aún más recientemente La escuela unitaria que con propuestas de renovación didáctica presentaba el profesor Jesús Jiménez en 1983. Podían acompañar a esos anteriores textos algunas referencias internacionales: el estudio de J. Braitwaite y de J. King sobre La enseñanza en escuelas de maestro único (1955) o también L'école a maître unique: recherche d'éducation comparée del Bureau International d’Éducation (1961).

A pesar de la defensa que los americanos Goodlad y Anderson venían haciendo desde 1949 en favor de la "escuela sin grados» ${ }^{51}$ y de su eficacia organizativa y pedagógica, lo cierto es que desde los pasados años sesenta se había intensificado la corriente que favorecía la graduación escolar, que llegó a considerarse como parte de una "cultura mundial» de la escuela y como parámetro de evaluación de los logros educativos en todos los países, como modelo organizativo asentado sobre la homogeneización, la estandarización, las economías de escala y sobre la lógica del «progreso y la modernidad».

\footnotetext{
${ }^{50}$ Estigmatizando las «escuelas rurales» al valorar que los alumnos rurales accedían más dificilmente al final de su escolaridad primaria, por lo que habría que proceder a los reagrupamientos y a la graduación, siguiendo, por otra parte, una lógica política economicista.

${ }^{51}$ John Goodlad y Robert H. Anderson, La escuela sin grados: organización y funcionamiento (Buenos Aires: El Ateneo, 1975).
} 
Elsie Rockwell haciéndose eco del estudio elaborado para América del Norte por Tyack y Cuban (En busca de la utopía. Un siglo de reformas en la escuelas públicas), publicado en 1995, hizo notar que la estructura graduada, estandarizada paulatinamente como modelo de expansión de las instituciones educativas y de los sistemas nacionales de educación occidentalizados, impuso reglas administrativas, de evaluación y curriculares que configuraron las rutinas de la vida escolar. ${ }^{52}$

Solo más recientemente dicho modelo de graduación ha venido a ser revisado, al apreciar los valores didácticos de la no graduación en favor de la mejor individualización y también del desarrollo de una didáctica atenta a las varias posibilidades de acción grupal, dando reconocimiento a las orientaciones trazadas en obras de Lee Smith y traducidas al castellano ya en $1974 .{ }^{53} \mathrm{Al}$ respecto, Sylvie Jouan se preguntaba recientemente desde Francia si un grupo de alumnos de varias edades no sería, por acaso, el mejor horizonte escolar. ${ }^{54}$ Roser Boix, Salvador Berlanga y Antonio Bustos vienen, por su parte, defendiendo esta perspectiva. ${ }^{55}$

Una historia de las prácticas escolares y del currículum, hacia la que se observa una creciente atención por parte de los investigadores habrá de considerar con mayor detenimiento, entre otros, los aspectos aquí indicados, percibiendo la proximidad o la distancia entre las orientaciones políticas y académicas y la realidad empírica, así como las lógicas intervinientes, a fin de lograr un mejor conocimiento sobre ese microcosmos que han sido las escuelas rurales, un microcosmos «situado».

${ }^{52}$ Elsie Rockwell «Las escuelas unitarias en México en perspectiva histórica: un reto aún vigente», Revista Mexicana de Historia e la Educación, 2 (3), (2014): 1-24.

${ }^{53}$ Lee Smith, Como enseñar en la escuela sin grados (Barcelona: Estrada, 1974) y La realidad de la escuela sin grados (Barcelona: Estrada, 1974).

${ }^{54}$ Sylvie Jouan, Classe multiâge d'hier à aujourd hui. Archaïsme ou école de demain, (París: ESF Ed., 2015).

${ }^{55}$ Roser Boix (coord.), La escuela rural: funcionamiento y necesidades (Madrid: CissPraxis, 2004); Salvador Berlanga Quintero, Educación en el medio rural: análisis, perspectivas y propuestas (Zaragoza: Mira Editores, 2003); Antonio Bustos, La escuela rural (Barcelona: Octaedro, 2011); Antonio Bustos, «Aproximación a las aulas de escuela rural: heterogeneidad y aprendizaje en los grupos multigrado", Revista de Educación, 352 (2010): 353-378. Como nos referimos aquí al caso español conviene decir que la política de concentraciones escolares oficialmente impulsadas durante los años setenta y primeros ochenta del siglo pasado se modificó a partir de 1983 al iniciarse el apoyo a las escuelas unitarias e incompletas, a lo que siguieron varias iniciativas con la intención de promover la educación compensatoria, en donde hay que encajar la creación de los Colegios Rurales Agrupados. 


\section{¿QUÉ OPORTUNIDADES PARA EL ALUMNADO DE LAS ESCUELAS RURALES?}

La desigualdad y la discriminación del alumnado anida en los ámbitos rurales, provocando procesos de minoración que pueden influír negativamente en sus expectativas, estrategias y valoraciones. Diversas constataciones empíricas y cuidados estudios analíticos vienen poniendo de relieve que las oportunidades académicas del alumnado de las escuelas en contexto rural son, en términos sociológicos, menores que las de aquellos que acuden a escuelas en espacios urbanos, de modo que sus posibilidades de recorrido escolar son menores, viéndose negativamente afectadas su movilidad social ascendente y la legítima búsqueda de equidad y de inclusión social. ${ }^{56}$

Hace décadas que este interrogante está bien presente, por ejemplo, en los trabajos y encuestas de la Federation Nationale pour l’École Rurale y de la Federation des Delegués Departamentaux de l’Éducation Nationale, como se refleja en particular en el estudio L'école en milieu rurale de 1995. ${ }^{57}$ Más recientemente el Observatoire de l’École Rurale en Francia, con los valiosos trabajos de Yves Alpe y otros ${ }^{58}$ ha venido a profundizar ese estudio, planteando: "Existe-t-il un "deficit culturel" chez les eleves ruraux?», ${ }^{59}$ una cuestión respondida por Pierre Champollion en los siguientes términos «el territorio influye sobre la escuela, si bien algo me-

\footnotetext{
${ }^{56}$ Alexandre Mikhalevitch, «La jeunesse rurale et-elle défavorisée?. Societé post-industrielle, situation d'acculturation et handicap». Orientations. Essais de recherche en éducation, 46 (1973): 97-112. La cuestión está presente en BIE, «Education pour le developpement rural, Documentation et information Pedagogiques», Bulletin du BIE, 216 (1980): 5-106, en el monográfico «Education et ruralités» de la Revue International d'education de Sévres, 10 (1996): 23-138 y de modo actualizado en un dossier similar organizado por la Revue International d'education de Sévres, 59 (2012): 35-135. Está también presente en David Atchoarena, Lavinia Gasperini, Educación para el desarrollo rural: hacia nuevas respuestas de política (Roma \& París: FAO \& UNESCO/IIPE, 2004).

${ }^{57}$ Françoise Oeuvrard (ed.), «Le système éducatif en milieu rural», Éducation et formations, 43 (1995): 5-155. También, Ministere de l’Éducation National, de l'enseignement supérieur, de la recherche et de l'insertion professionnelle, "Les zones d'habitat dispersé: un handicap pour les études?», en Rapport 1995 Inspection générale de l'administration de l'Education nationale (Paris: La Documentation française, 1995): 55-100.

${ }^{58}$ Yves Alpe, Jean-Luc Fauguet, Sociologie de l'école rurale (París: L’Harmattan, 2008); Yves Jean (dir.), Géographies de l'école rurale: acteurs, réseaux et territoires (París: Ophrys, 2007); Yves Alpe, Pierre Champollion, Jean-Louis Poirey (coords.), L'enseignment scolaire en milieu rural et montanarg (Besançon: Presses Universitaires de Franche-Comté, 2010).

${ }^{59}$ Yves Alpe, «Existe-t-il un "deficit culturel” chez les eleves ruraux?», Revue Fraçaise de Pedagogie, 156 (2006): 75-88.
} 
nos intensamente que el origen social», ${ }^{60}$ afirmando también la tesis de Duru Bellat: «le contexte fait les differences». ${ }^{61}$ Es decir, hay un « efecto territorio», que toma en cuenta las más diversas prácticas culturales y sociales, que influencia de modo multifactorial, global y sistémico, el desarrollo educativo del alumnado infantil en los espacios rurales.

Las evaluaciones parecen indicar que el medio rural concentra mayores dificultades para su rendimiento escolar, derivado de las características socio-profesionales y culturales de su población; no parece que sea el medio rural en sí un condicionante negativo de las prácticas culturales y del rendimiento escolar, sino la mayor concentración de un origen social más modesto del alumnado, lo que en expresión de Yves Alpe impone a las escuelas rurales extremar la atención a los objetivos que tienen asignados legislativamente, para la búsqueda de la igualdad de oportunidades, de modo que cuando esto ocurre «se evidencia un excelente resultado de la escuela rural si se considera que la estructura del origen social del alumnado rural y montañés es a priori predictivo de un resultado inferior» ${ }^{62}$ lo que debería llevar a realizar intervenciones de discriminación positiva (una educación compensatoria de orientación ecológica), cuidando con esmero las prácticas docentes y los programas escolares y evitando la tentación del «traslado a la ciudad» del alumnado rural.

Es lo que sugiere igualmente el estudio de Santiago Prado realizado en tierras rurales de Galicia: Terra de Melide: oportunidades educativas y desarrollo comunitario. Constata en una parte del alumnado que realiza la secundaria básica:

que es susceptible de abandono escolar ante el bajo rendimiento que presenta, por no contar con suficiente capital académico [nos referimos al legitimado escolarmente] en su ámbito familiar y por disponer de conocimientos no valorados en la institución escolar, [pero que podría no ser así y obtener] un mayor rendimiento si en la institución escolar se visibilizasen sus propias

\footnotetext{
${ }^{60}$ Pierre Champollion, «El impacto del territorio en la educación. El caso de la escuela rural en Francia», Profesorado. Revista del currículum y formación del profesorado, 2 (2011): 67.

${ }^{61}$ Marie Duru-Bellat \& Alain Mingat, «Le déroulement de la scolarité: le contexte fait des différences», Revue Française de Sociologie, 29 (1998), 649-666.

62 Pierre Champollion, «El impacto del territorio en la educación», 62.
} 
condiciones de existencia, pudiendo generar a su vez un mayor desarrollo comunitario. ${ }^{63}$

Conviene señalar que una mejor respuesta a los interrogantes que aquí se plantean es probable que se pudiese obtener desde la investigación histórico-educativa. Aún falta mucho por hacer al respecto, aunque se ha mostrado cómo la educación en los medios rurales, desarrollada desde esquemas culturales y lógicas de financiamiento y administrativas armadas desde las ciudades, ponen en desventaja a la población que vive en espacios rurales, situación que se ha agravado a raíz de la dificultad de hacer llegar las instituciones educativas a zonas dispersas.

\section{EDUCACIÓN, TERRITORIOS Y COMUNIDADES}

Los vínculos entre la educación y las escuelas, por una parte, y los territorios y las comunidades, por otra, son múltiples y complejos, se sostenía recientemente (2015) desde Sisyphus. Journal of Education. ${ }^{64}$ Hace ya décadas que se viene poniendo de manifiesto la importancia de considerar de un modo global los territorios, el sistema escolar y el desarrollo comunitario. En la Conferencia Internacional de Educación celebrada en Ginebra en 1961 se aprobaban, en tal sentido, las Recommendations of the Ministries of Education Concerning the Organization of One-Teacher Primary Schools, y es oportuno recordar que el Informe de Vanden Bossche para la Conferencia de 1963 se centraba en las Community Schools, ${ }^{65}$ con indicaciones reafirmadas en 1968 bajo el lema Community schools in developing countries. ${ }^{66}$

Desde aquellos momentos no ha dejado de preocupar como integrar las agencias escolares en el marco de las estrategias de desarrollo local y comunitario, con una perspectiva abierta en cuanto a la vida escolar y el papel de los docentes, sosteniendo que la escuela, en el corazón del habi-

\footnotetext{
${ }^{63}$ Santiago Prado Conde, «Terra de Melide: Oportunidades educativas y desarrollo comunitario» (Tesis doctoral, Universitat Autónoma de Barcelona, 2006), 499.

${ }^{64}$ La publicación académica del Instituto de Educación de la Universidad de Lisboa Sisyphus. Jounal of Education dedicó el siguiente volumen a la cuestión: Roser Boix, Pierre Champollion y Antonio M. Duarte (coords.), «Territorial specificities of Teaching and Learning», 3 (2), (2015).

${ }^{65}$ Jean Vanden Bossche, Las escuelas comunitarias (Buenos Aires: Paidós, 1969).

${ }^{66}$ Harold Houghton, y Peter Tregear (eds.), Community schools in developing countries (Hamburg: Institute for Education, 1969).
} 
tat rural, debería desarrollarse como un hogar permanente de cultura y de vida, con un papel estratégico. ${ }^{67}$ Es una propuesta que, como comentamos, viene por lo menos desde principios del siglo Xx, que se desarrolló con amplitud en varios países (como México y Bolivia) y se ha sostenido, a modo de ejemplo, en la propuesta que hace ya más de 20 años lanzaba desde Francia Bernard Charlot con su texto L'école et le territoire, ${ }^{68}$ que venía antecedida por una intensa actividad desarrollada al respecto desde el Consejo de Europa. ${ }^{69}$

Desde unos lugares u otros se vienen suscitando reflexiones, experiencias y evaluaciones en torno a esta interrelación. A menudo, surgidas a partir de las propias comunidades interesadas, en ocasiones merced a los programas de desarrollo local emprendidos por distintos gobiernos, sea por impulso de sectores académicos, ${ }^{70} \mathrm{o}$ de redes con sus publicaciones y congresos. ${ }^{71}$ Es oportuno, a este respecto, destacar el papel de organismos internacionales, como por ejemplo el Instituto Internacional de Planificación Educativa, la Oficina Internacional de Educación u otras

\footnotetext{
${ }^{67}$ Tomás Díaz González, «La cultura como factor estratégico del desarrollo local», Revista de Educación, 322 (2000): 69-88; Alberto Melo, «Educación y formación para el desarrollo local», Revista de Educación, 322 (2000): 89-100.

${ }^{68}$ Bernard Charlot, L'école et le territoire. Nouveaux espaces, nouveaux enjeux (París: Armand Colin, 1994).

${ }^{69}$ William Douglas Scott (ed.)/Conseil de l'Éurope, Campagne Européenne pour le monde rural (19871988). Vingt années d'action en faveur du monde rural (Strasbourg, 1988).

${ }^{70}$ Los estudios sobre las relaciones entre la escuela y la comunidad han tenido un gran impulso desde los años setenta en América Latina, especialmente en México, desde los campos de la historia de la educación y la antropología. Cabe mencionar en especial: Mary Kay Vaughan, Política cultural en la Revolución Mexicana: maestros, campesinos y escuelas en México. 1930-1940 (México, SEP, 2000); Susana Quintanilla y Mary Kay Vaughan (coords.), Escuela y sociedad en el periodo cardenista (México: Fondo de Cultura Económica,1997); Guillermo Palacios, La pluma y el arado: los intelectuales pedagogos y la construcción sociocultural del problema campesino en México, 1932-1934 (México: El Colegio de México y CIDE, 1999); Elsie Rockwell, Hacer escuela, hacer estado. La educación posrevolucionaria vista desde Tlaxcala (México: El Colegio de Michoacán, Ciesas y Cinvestav), y Luisa Paré y Elena Lazos Chavero, Escuela rural y organización comunitaria. Instituciones locales para el desarrollo y el manejo ambiental (México: Plaza y Valdés, 1999). Una bibliografía amplia puede verse en Juan Alfonseca, «La historia de la educación rural en México, 1920-1970», en Luz Elena Galván, Susana Quintanilla y Clara Inés Ramírez, Historiografía de la Educación en México (México: COMIE 2003): 279-314.

${ }^{71}$ Como la Red Temática de Investigación de Educación Rural de México, los Seminarios Internacionales de Investigación sobre Educación Rural celebrados en el Uruguay, las Jornades d’Escola Rural dels mestres de Catalunya, que desde hace más de 20 años viene convocando el Secretariat d'Escola Rural de Catalunya, o los Encontros de debate sobre o medio rural que desde hace ya más de una década convoca Nova Escola Galega.
} 
agencias de la UNESCO. A través de todas estas dinámicas no solo la escuela se ve movilizada, sino también variados procesos de animación socio-cultural y la educación de los jóvenes y los adultos, derivando en el presente un crecido número de estudios y publicaciones. ${ }^{72}$

La consideración de los territorios y las comunidades y el horizonte del desarrollo local pueden tener en la consideración del patrimonio material e inmaterial local de la educación una fuente de apreciable valor. A este respecto, conviene señalar que una Historia de la Educación atenta a las prácticas culturales y atenta a la antropología cultural e histórica podrá hacer notables contribuciones, como han mostrado varios estudios en México. De hecho esas contribuciones ya vienen teniendo lugar alrededor de lugares como el Musée de l'École Rurale de la Bretagne en Francia, creado en 1986, una iniciativa que en la actualidad se extiende por otros lugares y comunidades, favoreciendo el estudio histórico, el diálogo intergeneracional y el desarrollo cultural y educativo local.

Llegados a este punto, hemos podido apreciar hasta seis distintos modos de observar desde la Historia de la Educación — quizás no solo desde ella- las posibles interrelaciones entre los procesos educativos y los contextos rurales. Además, hemos podido señalar cuestiones, referencias y posiciones susceptibles de ser analizadas o tomadas en consideración con la intención de avanzar en el conocimiento histórico-educativo, haciendo notar, por otra parte, la necesidad de intensificar los estudios comparados.

Es el momento de realizar una invitación a la lectura de las distintas aportaciones que hemos logrado reunir en el presente número monográfico de Historia y Memoria de la Educación.

El número inicia con un artículo en el que Lucía Lionetti, pese a la escasez de fuentes, se acerca al trabajo de las escuelas en la campaña bonaerense, en Argentina, durante la primera mitad del siglo XIX y las ubica dentro del proceso de formación del Estado nacional. Destaca cómo

\footnotetext{
${ }^{72}$ Se puede apreciar, por ejemplo, en Bernadette Plumelle, «Références bibliographiques du dossier «Éducation et ruralités», Revue internationale d'éducation de Sèvres, 59 (2012):125-135.
} 
pese a ser una región dinámica y en crecimiento, era vista por las élites como una zona rústica y triste. Entre el cambio del régimen, las guerras y le escasez de recursos, la escolarización fue impulsada por los notables locales, convencidos de la importancia de extender la alfabetización y la formación de ciudadanos. Pese a este consenso, existieron fuertes disputas en torno a los actores que debían regir lo educativo, los métodos y los contenidos. Por otra parte, la escolarización se toparía con la resistencia de los propios padres de familia para quienes la escuela, además de lejana, entorpecía la participación de los niños en las labores agrícolas cuando, además, no enseñaba nada que sirviera para su futuro.

El artículo que desde Italia ha preparado Luca Montecchi tiene como objetivo explicar el desarrollo histórico de la educación primaria impartida a los jóvenes campesinos italianos entre la Unificación nacional y la caída del Fascismo (1861-1943). En particular, pretende destacar las continuidades y los cambios en las políticas escolares promulgadas por el Gobierno Italiano en relación con las escuelas rurales, analizando - desde un punto de vista institucional - la evolución de la legislación y la historia de las instituciones estatales y privadas que fueron encargadas de organizar las escuelas para los jóvenes campesinos entre los siglos XIX y XX. Nos advierte sobre el pobre papel de las legislaciones estatales para afrontar la institucionalización de la forma escolar en los contextos rurales y sobre los conflictos, a menudo larvados, entre las intencionalidades estatales y las efectivas preocupaciones de los habitantes de estos contextos.

Por su parte, Juan Alfonseca, al analizar la escolarización de las áreas rurales en Santo Domingo, toca un tema muy importante: cómo la escuela pública orquestada desde el Estado parte de iniciativas de escolarización iniciadas desde la sociedad civil, que en este caso, llama la «escuela-aposento». Formas similares se encuentran en el origen de la escolarización de los medios rurales en muchos otros lugares: las escolas de ferrado analizadas por Narciso de Gabriel en Galicia son un ejemplo, o las escuelas amigas en México o las casas-escuela en Brasil, o el notable programa de creación de escuelas rurales en el País Vasco de las que hablan Garmendia, Zabaleta y Murua en este monográfico. En estos casos, la creación de la escuela pública implica la reapropiación por parte del Estado de estas iniciativas inciertas entre lo público y lo privado, restan- 
do fuerza a las iniciativas de la sociedad civil, así como legitimación al maestro «empírico», lo cual en este caso se hizo a partir de pedagogías ruralistas en la era de Trujillo.

En el artículo de Marco Calderón se aprecia cómo las pedagogías ruralistas sirvieron, durante el régimen de la revolución mexicana, para resolver lo que se presentaba como «el problema indígena». También aquí se observa la apropiación y descalificación desde el Estado de las manifestaciones culturales de la sociedad civil, en este caso, de los grupos indígenas, comenzando por su lengua. Las diferencias étnicas quedaron encerradas en la distinción entre lo urbano y lo rural promovida por la revolución y la escuela. "Lo rural» igual englobó a todos los grupos indígenas que a las poblaciones mestizas, poniendo énfasis en la forma de trabajar la tierra. La escuela rural se construyó en medio de debates políticos y pedagógicos, por medio de varias estrategias: las misiones culturales y las casas del pueblo, que buscaron colocar a la escuela en el centro de la comunidad, y como tal, como pilar de la construcción de una industria agrícola y de una nación mestiza con una sola lengua.

Al igual que en los casos anteriores, la construcción del Estado-Nación, la revolución industrial o la modernización, están en el centro de los conflictos por la escuela. En las áreas rurales, se busca alfabetizar, modernizar y homogeneizar a través de la escuela, pero a la vez, el Estado no presta atención suficiente a la periferia y lo rural, amplificando con ello las posibilidades de resistencia y los conflictos: la reivindicación indígena en México o el nacionalismo en el País Vasco. Las tensiones entre lo local y la construcción nacional, muy relacionadas con los niveles de administración de la escuela (privada-pública, local, provincial, nacional) se observa, como en otros casos, en el artículo de Jose Garmendia, Iñaki Zabaleta e Hilario Murua sobre las escuelas rurales vascas. La inasistencia escolar es acaso el arma más importante de los grupos locales para resistir los proyectos estatales y su insistencia en una lengua compartida. Ante la inasistencia, se tienen que adecuar las estrategias y mecanismos de los proyectos educativos. Así, lo podremos observar en este caso, tener que enseñar en vasco para hacer llegar la enseñanza de la doctrina en las escuelitas rurales.

En su artículo, Justino Magalhaes muestra cómo en Portugal hubo diversos debates y menciones a la necesidad de propiciar una educación 
con características propias en los medios rurales desde 1911 y sobre todo en los años treinta con la institucionalización del Estado Novo. Sin embargo, tanto durante la dictadura como durante el Estado Novo no alcanzó a perfilarse una definición política y pedagógica de una escuela rural, como tampoco hubo continuidad en cómo lo rural podía ser incluido en el currículum escolar.

Así, en Portugal se fueron multiplicando las instituciones para ampliar la oferta escolar en los medios rurales con estructuras casi siempre precarias y temporales, mientras lo rural se planteaba entre lo atrasado y arcaico y lo idílico y sano frente a un mundo urbano peligroso e inmoral. Con este recorrido podríamos preguntarnos por qué en el caso de Portugal, a diferencia de otras economías agrícolas, no llegó a armarse una propuesta de educación ruralista. Por una parte, el desarrollo de la escuela en los medios rurales se relaciona con las formas en que se concibe y proyecta lo rural (o las ruralidades), por otro, la escuela genera ciertas representaciones del mundo o los mundos rurales que han sido poco exploradas. Otra pregunta más, muy relacionada a las anteriores, se refiere a las relaciones entre alfabetización y escolarización en los medios rurales. Las discusiones sobre la educación rural, al plantearse la utilidad de la escuela para una población que se dedica a la agricultura, o una educación pensada según las características de sus usuarios, abrieron entre otros temas, un cuestionamiento acerca de la centralidad de la lengua escrita en la escuela.

Aquella conflictividad, a menudo larvada y latente, entre las orientaciones políticas educativas estatales, de una parte, y las necesidades de alfabetización y formación sentidas por las poblaciones locales, a la que nos referimos más arriba con ocasión de la aportación de Luca Montecchi, se presenta con fuerza singular y una luz crítica reveladora en la experiencia educativa italiana de Don Milani, un sacerdote rebelde. Un debate fuerte sobre el modelo de escuela, como refleja Carmen Betti en su aportación. La lettera a una professoressa, dada a conocer en 1967 ahora hace 50 años, fue un aldabonazo en la conciencia social y educadora en múltiples y distintos entornos. Una referencia viva en el debate sobre los proyectos de educación y su conexión con los proyectos de construcción de una ciudadanía activa y de sociedades democráticas. Desde una modesta escuela rural sus alumnos alcanzaban la capacidad de destripar 
las injusticias sociales y también la de mostrar la relevancia de una necesaria y distinta educación.

Desde principios del siglo xx se realizaron esfuerzos en distintos países para ofrecer una formación en materia agrícola no sólo a los propietarios de tierra en las escuelas profesionales, sino también a la población rural en general. Las escuelas granja en sus distintos niveles y modalidades, han sido importantes en la escolarización de la población en medios rurales. Su ligazón a lo rural las coloca en un prestigio menor a otras instituciones dentro del sistema educativo, pero en lo local suelen ser, según las circunstancias, fuentes no sólo de capacitación, formación y acreditación, sino motores de cambio cultural y de formación ciudadana en los que tienen mucho que ver los actores locales y sus afanes económicos y políticos. Precisamente la alta implicación de los actores locales en su sostenimiento les dan un poder simbólico de gran peso. María del Carmen Agulló y Andres Payá muestran en su artículo la experiencia de las escuelas agrícolas comarcales en Valencia como centros de educación democrática y renovación pedagógica - con referencias freinetianas y freirianas, en particular- desarrolladas en los últimos años de la dictadura franquista y la transición a la democracia. Proyectos relacionados con los sacerdotes, la organización de los trabajadores agrícolas y las primeras elecciones en ayuntamientos, que retomaron bases de la enseñanza agrícola (ligada al cooperativismo) que se desarrolló en las segunda y tercera década del siglo, en este caso de las Maisons Familiares d'Aprentissage Rural francesas. Metodologías como la alternancia, la tutoría y el cuaderno del medio se siguen utilizando en muchas instituciones de este tipo hasta nuestros días. La brevedad de la existencia de estas escuelas no elimina su importancia como motores de cambio, fuentes culturales (de ideas libertarias, democráticas, coeducativas, cooperativistas) y como experiencias alternativas sostenidas en buena medida por la sociedad civil.

Ésta, la sociedad civil, ha sido fundamental en el intento de cubrir el rezago educativo en las áreas rurales. Rodolfo Luis Ferradás y José Pablo Franco relatan cómo las Cáritas de Galicia desarrollaron entre 1977 y 2012 el Preescolar na Casa, una innovadora acción educativa que potencia la educación que los padres pueden dar a sus hijos cuando las escuelas preescolares están ausentes o son inadecuadas. Por medio de reuniones, publicaciones, la radio y la televisión — sorteando las limitaciones 
económicas- y con la utilización dominante de la lengua gallega en la comunicación, se ha promovido una cultura moderna de la infancia, con planteamientos educativos no convencionales.

Hemos podido incluir también una documentada experiencia de vida. María García Alonso nos ofrece una entrevista con el profesor uruguayo, de origen catalán, Manuel Soler Roca y un documento escrito por él. Ambos son riquísimos testimonios acerca de las ideas y del trabajo de un profesor muy importante para la educación rural en Uruguay, pero también del tipo de proyecto y de las contradicciones a las que se enfrentó la labor desplegada por la UNESCO con la educación fundamental y el CREFAL como centro de encuentro y formación de maestros para toda América Latina en la década de los sesenta. Los intentos de terminar con la miseria y mejorar las condiciones de vida de la población en los medios rurales a menudo se toparon con los límites impuestos por las formas de tenencia y explotación de la tierra. La labor económica, cultural, educativa, sanitaria que realizaban maestros tan preparados y comprometidos como Soler desde el núcleo escolar de la Mina, pese al cobijo de la UNESCO, muchas veces tuvo conflictos con los gobiernos locales o como en este caso, con la administración de la educación pública nacional. El anhelado cambio integral era difícil de conseguir de esta manera y ello en parte llevaría al abandono de la educación fundamental como política de la UNESCO años más adelante. Sin embargo, la riqueza de estas experiencias, que puede apreciarse en los documentos, sin duda dejaron huellas duraderas en las regiones en que se realizaron.

Como hemos dicho, aportaciones distintas en el tiempo, en los espacios, en las temáticas, así como en los tratamientos teórico-metodológicos y en las fuentes, que quizás contribuyan, como deseamos, a que nuestras miradas investigadoras puedan ir más allá de las instituciones y la forma escolar, y a que estos ejercicios analíticos y valorativos se «desnacionalicen» desde una observación abierta a la comparación.

\section{Referencias:}

Aganzo, Andrés, coord. Escuelas Campesinas: una experiencia que camina. Madrid: Cares, 1983.

Ahmed, Manzoor y Phillip Coombs. Education for rural development. Case Studies for Planners. New York: Praeger, 1975. 
AleXANDer, Thomas y Beryl PARKer. La Nueva Educación en la República Alemana. Madrid: Aguilar, 1931.

AlfonsecA, Juan. "La historia de la educación rural en México, 1920-1970». In Historiografía de la Educación en México, edited by Luz Elena Galván, Susana Quintanilla y Clara Inés Ramírez, 279-314. México: COMIE, 2003.

Almendros, Herminio. Carta a un maestro de una escuela rural. La Habana: Ministerio de la Educación, 1960.

Alpe, Yves y Jean-Luc Fauguet. Sociologie de l'école rurale. París: L’Harmattan, 2008.

Alpe, Yves, Pierre Champollion y Jean-Louis Poirey (coords.). L'enseignment scolaire en milieu rural et montanarg. Besançon: Presses Universitaires de Franche-Comté, 2010.

Alpe, Yves. "Existe-t-il un "deficit culturel" chez les eleves ruraux?». Revue Fraçaise de Pedagogie 156 (2006): 75-88.

ATCHOARENA, David y Lavinia GASPERINI. Educación para el desarrollo rural: hacia nuevas respuestas de politica. Roma \& París: FAO \& UNESCO/IIPE, 2004.

Barnita, Bagchi, Fuchs EcKhardt and Kate Rousmaniere, eds. Connecting Histories of Education: transnational and cross-cultural exchanges in (Post) Colonial Education. New York-Oxford: Berhahn, 2014.

BERLANGa QuINTERo, Salvador. Educación en el medio rural: análisis, perspectivas y propuestas. Zaragoza: Mira Editores, 2003.

BERnard, Charlot. L'école et le territoire. Nouveaux espaces, nouveaux enjeux. París: Armand Colin, 1994.

BIE. «Education pour le developpement rural, Documentation et Information Pedagogiques». Bulletin du BIE 216 (1980): 5-106.

BoIx, Roser, coord. La escuela rural: funcionamiento y necesidades. Madrid: CissPraxis, 2004.

Boix, Roser, Pierre Champollion y Antonio M. DuARTE, coords. «Territorial specificities of Teaching and Learning». Sisyphus. Jounal of Education 3 (2), (2015): 7-11.

BorsotTI, Carlos A. Sociedad rural, educación y escuela en América latina. Buenos Aires: Kapeluz, 1984.

Bustos, Antonio. "Aproximación a las aulas de escuela rural: heterogeneidad y aprendizaje en los grupos multigrado». Revista de Educación 352 (2010): 353-378.

- La escuela rural. Barcelona: Octaedro, 2011.

Camarero, Luis A. Del éxodo rural y del éxodo urbano: ocaso y renacimiento de los asentamientos rurales en España. Madrid: Ministerio de Agricultura y Pesca, 1993. 
CARABAÑA, Julio. "¿Tiene la escuela rural que formar alumnos rurales?». Revista de Estudios de la Juventud 18 (1985): 37-45.

CARMElo García, Juan. «El estado de la educación rural en América Latina y en África». Revista de Educación 322 (2000): 119-142.

CARMena, Gregoria y Jesús R. RegIDOR. La escuela en el medio rural. Madrid: Ministerio de Educación y Ciencia, 1984.

CAVICCHIONI, Vittoria y Anna ERIKSON. Urban and rural school: special survey on primary education. París: UNESCO, 1992.

Champollion, Pierre. «El impacto del territorio en la educación. El caso de la escuela rural en Francia». Profesorado. Revista del currículum y formación del profesorado 15 (2), (2011):53-69.

Civera, Alicia, Juan Alfonseca y Carlos Escalante, coords. Campesinos y escolares. La construcción de la escuela en el campo latinoamericano (siglos XIX y XX). México: Miguel Ángel Porrúa y El Colegio Mexiquense, 2011.

CIVERA, Alicia. "Range and limits of rural school historiography in Latin America: 19th and 20th Centuries. Some Reflections». In Connecting Histories of Education: transnational and cross-cultural exchanges in (Post) Colonial Education, edited by Barnita Bagchi, Eckhardt Fuchs and Kate Rousmaniere, 61-82. New York-Oxford: Berhahn, 2014.

- «Entre lo local y lo global. La Unesco y el proyecto educativo piloto de México 1947-1951». Annali di storia dell'educazione 22 (2015):166-179.

- «Los libros sobre la educación rural en México publicados en el nuevo siglo: una revisión general». In Historia e historiografia de la educación en México. Hacia un balance 2002-2011, vol.II, edited by María Esther Aguirre Lora, 249-271. México: COMIE y ANUIES, 2016.

CORREA Weerle, Flávia OBINO, coord. Educação rural em perspectiva internacional. Instituções, prácticas e formação do professor. Ijuí: Universidade Regional do Noroeste do Estado do Rio Grande do Sul, 2007.

Costa Rico, Antón. «Escolas en contornas rurais en Galicia: horizonte dificil/ horizonte posible». Innovación Educativa 24 (2014): 133-153.

- «Luis F. Iglesias (1915-2010), pedagogo latinoamericano, Galicia e Nova Escola Galega, con Jesualdo ao fondo». Innovación Educativa 26 (2016): 305-321.

Díaz GonzÁlez, Tomás. «Escuelas Campesinas de Ávila: animación socio-cultural en el medio rural». Revista de Estudios de Juventud 18 (1985): 195-210.

- «La cultura como factor estratégico del desarrollo local». Revista de Educación 322 (2000): 69-88.

DREYFus, Amos. «Agricultural and Rural Education». In The International Encyclopedia of Education, edited by Torsten Husen y Neville Postlethwaite, 240244. Oxford: Pergamon, 1994. 
Duru-Bellat, Marie y Alain Mingat. «Le déroulement de la scolarité: le contexte fait des différences». Revue Française de Sociologie 29 (1998): 649-666.

EKANAYAKE, Wasantha. «La pédagogie en zone rurale: comment promouvoir le développement rual à la base». Perspectives 1 (1990):129-143.

FAO, UNESCO, CIDE. Educación para la población rural en Brasil, Chile, Colombia, Honduras, México, Paraguay y Peru. Roma: FAO, 2004.

FERnÁndez Soria, José M. y María del Carmen Agulló DíAz. Una escuela rural republicana. Valencia: Universidad de Valencia, 2004.

FonTE, Ramiro. Os meus ollos. Vigo: Edicións Xerais de Galicia, 2004.

Froeschlé, Michel. L'école au village: les petites écoles de l'Ancien Régime à Jules Ferry. Nice: Serre, 2007.

FURTER, Pierre. Os sistemas de formaçâo em seus contextos. Introduçâo a um metodo de educaçâo comparada. Rio de Janeiro: Editora da Fundaçâo Getulio Vargas, 1982.

- Les espaces de la formation. Essai de microcomparaison et de microplenfication. Lausanne: Presses Polytechniques Romandes, 1983.

GAuthier, Pierre-Louis y Odile LuginbüHL. "L'éducation en milieu rural: percepcións et realités». Revue Internationale d'éducation de Sèvres 59 (2012): 35-42.

GERDENITSCH, Claudia y Johanna HopfNER, eds. Erziehung und bildung in lândlichen regionen. Austria: Peter Lang, 2010.

GIRAUDO, Laura, coord. «Dossier. Forjando un México nuevo. Revolución, nación y cultura en el México posrevolucionario». Anuario de Estudios Americanos 67 (2), (2010): 415-787.

GoOdLAD, John y Robert H. ANDERSON. La escuela sin grados: organización y funcionamiento. Buenos Aires: El Ateneo, 1975.

Gonzalbo, Pilar y Gabriela Ossenbach, coords. Educación rural e indígena en Iberoamérica. México: El Colegio de México y UNED, 1999.

GonZÁlEZ, Teresa. coord. Educación rural en Iberoamérica. Experiencia Histórica y construcción de sentido. España: Anroat, 2009.

GRANDE, Miguel. La escuela rural: situación educativa en el medio castellano-leonés. Granada: Editorial Popular, 1981.

GrosPERrin, Bernard. Les petites ecoles sur l'Ancien Régime. Rennes: Ouest France, 1984.

Houghton Harold y Peter TREgear, eds. Community schools in developing countries. Hamburg: Institute for Education, 1969.

IgLESIAS, Luis Fortunato. Aprendizaje vivencial de la lectura y la escritura. Buenos Aires: Ediciones Pedagógicas, 1987.

- «En la escuela no se enseña a estudiar sino se enseña a pensar». Novedades educativas 26 (1992). 
ILON, Lynn and Peter MoocK. "School atributes, house hold characteristics, and demand for schooling: a case study of rural Peru». International review of education 4 (1991): 429-451.

JEAn, Yves, ed. Géographies de l'école rurale: acteurs, réseaux et territoires. París: Ophrys, 2007.

JiméNez Mier TERÁN, Fernando. Un maestro singular: vida, pensamientro y obra de José de Tapia. México: Jiménez Mier, 1996.

Jounn, Sylvie. Classe multiâge d'hier à aujourd'hui. Archä̈sme ou école de demain. París: ESF, 2015.

Knipmeyer, Mary, Marta GonzÁlez Bueno y Teresa SAn Roman. Escuelas, pueblos y barrios (Antropología educativa). Madrid: Akal,1980.

LACRUZ AlCOCER, Miguel. Entre surcos y pupitres. Historia de la educación agraria en la España de Franco. Madrid: Endymion, 1997.

— «Aulas entre rastrojos». Revista de Educación 322 (2000):11-27.

Lionetti, Lucía, Alicia Civera y Flávia Obino Correa Werle, coords. Sujetos, comunidades rurales y culturas escolares en América Latina. Argentina: Editorial Pro-historia-El Colegio de Michoacán y El Colegio Mexiquense, 2013.

Lodi, Mario. El país errado. Barcelona: Laia, 1975.

Luzuriaga, Lorenzo. Pedagogia social e política. Sâo Paulo: Companhia Editora Nacional, 1960.

MARquÉs SuREDA, Salomò, ed. Un poble, una escola, una revista: la revista Inquitud de l'escola de Menàrguens. Lleida: Ajuntament de Menàrguens, 2010.

Martín Luengo, María Josefa. Fregenal de la Sierra: una experiencia de escuela en libertad. Madrid: Campo Abierto, 1978.

MELo, Alberto. «Educación y formación para el desarrollo local». Revista de Educación 322 (2000): 89-100.

Mikhalevitch, Alexandre. «La jeunesse rurale et-elle défavorisée?. Societé post-industrielle, situation d'acculturation et handicap». Orientations. Essais de recherche en éducation 46 (1973): 97-112.

Ministere de l'Éducation National, de l'enseignement supérieur, de la recherche et de l'insertion professionnelle. «Les zones d'habitat dispersé: un handicap pour les études?». In Rapport 1995 Inspection générale de l'administration de l'Education national, 55-100. Paris: La Documentation française, 1995.

MiNisterio de EdUCACIÓN y CiENCIA. La educación infantil en el medio rural. Madrid: Ministerio de Educación y Ciencia, 1990.

Molino, Sergio del. La España vacía. Viaje por un país que nunca fue. Madrid: Turner, 2016.

Montecchi, Luca. I contadini a scuola. La scuola rurale in Italia dall'Unità alla caduta del fascismo. Macerata: EUM - Edizioni Università di Macerata, 2015. 
OEuVRARD, Françoise, ed. «Le système éducatif en milieu rural». Éducation et formations 43 (1995): 5-155.

Oficina InTERnacional de Educación. La Escuela Secundaria Básica en el Campo: una innovación educativa en Cuba. París: UNESCO, 1974.

Palacios, Guillermo. La pluma y el arado: los intelectuales pedagogos y la construcción sociocultural del problema campesino en México, 1932-1934. México: El Colegio de México y CIDE, 1999.

PARÉ, Luisa y Elena LAzos CHAVERo. Escuela rural y organización comunitaria. Instituciones locales para el desarrollo y el manejo ambiental. México: Plaza y Valdés, 1999.

PÉREz DíAz, Víctor. Emigración y cambio social: procesos migratorios y vida rural en Castilla. Barcelona: Ariel, 1971.

Pla Cargol, Joaquín. La Escuela Activa. "Colección Biblioteca de Pedagogía Moderna». Gerona: Dalmau Carles Pla Editores, 1933.

Plumelle, Bernadette. «Références bibliographiques du dossier «Éducation et ruralités»». Revue internationale d'éducation de Sèvres 59 (2012): 125-135.

Pozo Andrés, María del Mar. «Desde l’Hermitage a la escuela rural española: introducción, difusión y apropiación de los “centros de interés” decrolianos (1907-1936)». Revista de Educación, Número extraordinario (2007): 143-166.

PRADo Conde, Santiago. «Terra de Melide: Oportunidades educativas y desarrollo comunitario».PhD diss., Universitat Autónoma de Barcelona, 2006.

Prieto Ortega, Miguel Ángel. La pariente pobre (Significante y significados de la escuela rural). Madrid: MEC/CIDE, 1995.

Quintanilla, Susana y Mary Kay VAughan, coords. Escuela y sociedad en el periodo cardenista. México: Fondo de Cultura Económica, 1997.

RAYMAERKERS, Erik y Myriam BACQUELAINE. "Una educación integrada de base para el desarrollo rural». Perspectivas 3 (1985): 487-502.

RocKWELL, Elsie. Hacer escuela, hacer estado. La educación posrevolucionaria vista desde Tlaxcala. México: El Colegio de Michoacán, Ciesas y Cinvestav, 2008.

RocKWELL, Elsie y Claudia GARAY. «Las escuelas unitarias en México en perspectiva histórica: un reto aún vigente». Revista Mexicana de Historia e la Educación 2 (3), (2014): 1-24.

Rodríguez Barreira, Oscar. Pupitres vacíos. La escuela rural de la postguerra. Almería, 1939-1953. Almería: Instituto de Estudios Almerienses, 2015.

Serrano Lacarra, Carlos. Despoblación y territorio. Zaragoza: Centro de estudios sobre la despoblación y desarrollo de áreas rurales, 2007.

Sмiтh, Lee. Cómo enseñar en la escuela sin grados. Barcelona: Estrada, 1974.

- La realidad de la escuela sin grados. Barcelona: Estrada, 1974.

SouzA, María Antonia de. «La Educación del Campo y la experiencia colectiva de los movimientos sociales: Indagando sobre la Educación Rural en Brasil». 
In Sujetos, comunidades rurales y culturas escolares en América Latina, edited by Lucía Lionetti, Alicia Civera y Flávia Werle, 163-178. Argentina: Editorial Pro-historia-El Colegio de Michoacán y El Colegio Mexiquense, 2013.

SubIRATS. Marina. L'escola rural a Catalunya. Barcelona: Rosa Sensat/Edicions 62, 1983.

Sujomlinski, Vasili. Pensamiento pedagógico. Moscú: Ediciones Progreso, 1975. Torres Bodet, Jaime. Discurso de la Unesco. México: SEP, 1987.

VAnden Bossche, Jean. Las escuelas comunitarias. Buenos Aires: Paidós, 1969. Vaughan, Mary Kay. Política cultural en la Revolución Mexicana: maestros, campesinos y escuelas en México. 1930-1940. México: SEP, 2000.

VIGNER, Gérard, et al. "Scolarisation et monde rural: dossier». Diagonales 37 (1996): 14-35. 